\title{
THE BIG PICTURE
}

\section{From conference centre to hospital}

\author{
Tom Moberly
}

The BMJ

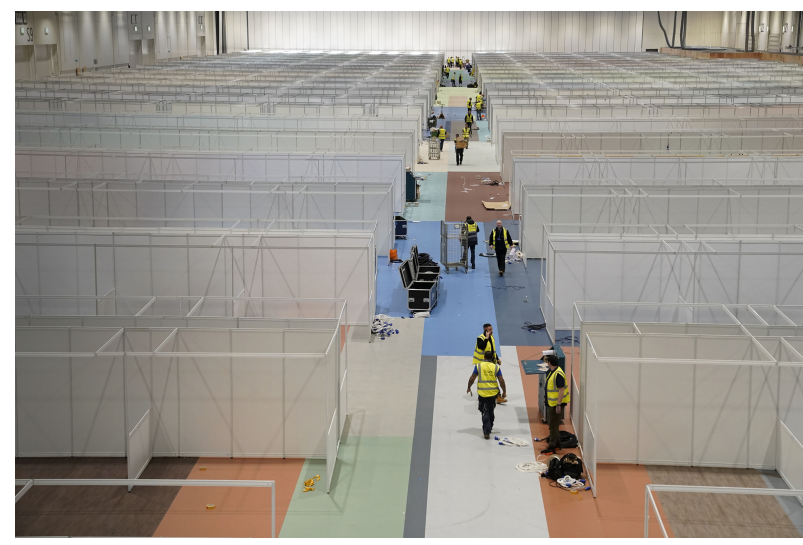

[Image: Andrew Parsons /10 Downing Street/Anadolu Agency /Getty Images]

Teams begin work setting up the Nightingale Hospital London at the Excel conference centre in east London on 27 March 2020 .
Military personnel were involved in the planning stages of the project to establish the hospital and are continuing to support NHS England by providing infrastructure, logistics, and project management advice. The hospital has been established to provide support for thousands of patients with covid-19, and the conference centre has been refitted to take hundreds of beds with oxygen and ventilators.

Two further NHS Nightingale hospitals will open in Birmingham and Manchester. A hospital based at the National Exhibition Centre in Birmingham will start with up to 500 beds and will be equipped to increase capacity to up to 2000 beds if needed. A hospital based at the Manchester Central Complex will provide up to 500 beds but could expand further to 1000 beds for coronavirus patients across northwest England.

In New York, Central Park is the location for one of several temporary hospitals being erected to support hospitals treating covid-19 patients in the US. The hospital has been set up by the Mt Sinai hospital system with 68 beds. 